\title{
Multivariate modeling of chromium-induced oxidative stress and biochemical changes in plants of Pistia stratiotes $\mathbf{L}$.
}

\author{
Sarita Sinha · Ankita Basant - Amrita Malik • \\ Kunwar P. Singh
}

Accepted: 8 April 2009/Published online: 25 April 2009

(C) The Author(s) 2009. This article is published with open access at Springerlink.com

\begin{abstract}
Biochemical changes in the plants of Pistia stratiotes L., a free floating macrophyte exposed to different concentrations of hexavalent chromium $(0,10,40$, $60,80$ and $160 \mu \mathrm{M})$ for 48,96 and $144 \mathrm{~h}$ were studied. Chromium-induced oxidative stress in macrophyte was investigated using the multivariate modeling approaches. Cluster analysis rendered two fairly distinct clusters (roots and shoots) of similar characteristics in terms of their biochemical responses. Discriminant analysis identified ascorbate peroxidase (APX) as discriminating variable between the root and shoot tissues. Principal components analysis results suggested that malondialdehyde (MDA), superoxide dismutase (SOD), APX, non-protein thiols (NP$\mathrm{SH}$ ), cysteine, ascorbic acid, and Cr-accumulation are dominant in root tissues, whereas, protein and guaiacol peroxidase (GPX) in shoots of the plant. Discriminant partial least squares analysis results further confirmed that MDA, SOD, NP-SH, cysteine, GPX, APX, ascorbic acid and Cr-accumulation dominated in the root tissues, while
\end{abstract}

\section{S. Sinha $(\square)$}

Ecotoxicology and Bioremediation Group, National Botanical Research Institute (Council of Scientific \& Industrial Research), Rana Pratap Marg, Lucknow 226001, India

e-mail: sinha_sarita52@yahoo.com

\section{A. Basant}

AAIDU, Allahabad, India

\author{
A. Malik $\cdot$ K. P. Singh \\ Environmental Chemistry Division, Indian Institute of \\ Toxicology Research, (Council of Scientific \& Industrial \\ Research), Post Box 80, MG Marg, Lucknow 226001, India \\ Present Address: \\ A. Basant \\ Department of Chemistry and Chemical Biology, Rutgers \\ University, Piscataway, NJ, USA
}

protein in the shoot. Three-way analysis helped in visualizing simultaneous influence of metal concentration and exposure duration on biochemical variables in plant tissues. The multivariate approaches, thus, allowed for the interpretation of the induced biochemical changes in the plant tissues exposed to chromium, which otherwise using the conventional approaches is difficult.

Keywords Pistia stratiotes L. · Chromium · Oxidative stress · Biochemical responses . Multivariate modeling

\section{Introduction}

Metals are known to induce oxidative stress in the plants (Singh et al. 2004b, c). Chromium (Cr), a transition metal, contaminates both the soil and water ecosystems in the disposal areas (Sinha et al. 2006). It has been demonstrated to induce oxidative stress through formation of free-radicals and reactive oxygen species (ROS; Stohs and Bagchi 1995) and causes plant membrane damage, ultra-structural changes in organelles, impaired metabolic activities and growth retardations (Kimbrough et al. 1999). To eliminated or reduce such damaging effects, the plant defense system is equipped with both enzymatic and non enzymatic mechanisms to scavenge free radicals (Foyer and Nocter 2003). Anti-oxidative enzymes include superoxide dismutase (SOD), peroxidase (POD) and catalase (CAT) and antioxidant compounds include glutathione (GSH), cysteine, nonprotein thiols (NPSH), ascorbic acid and cartenoids, etc. (Larson 1988). Cell oxidative stress levels are determined by the amounts of ${ }^{\bullet} \mathrm{O}^{2-}, \mathrm{H}_{2} \mathrm{O}_{2}$ and ${ }^{\circ} \mathrm{OH}$ radicals (Foyer and Nocter 2003). The balance between free radical generation and free radical defense are crucial for the survival of the 
plant. The response of these anti-oxidative enzymes and anti-oxidants to metal stress varies among the plant species and the metal involved (Mazhoudi et al. 1997).

Metal-induced oxidative stress in the plants has generally been studied through their biochemical responses and interpreted in terms of their variation trends and patterns as observed through conventional visual perception (Schutzendubel et al. 2002). Interpretation and conclusions reached through such an approach are most of the times unclear and less conclusive due to complex nature of biochemical responses and their inter-relationships. The traditional data analysis techniques are oriented primarily toward the extraction of quantitative data characteristics, and as such have inherent limitations. These techniques cannot produce conceptual descriptions of dependencies among data items or explain reasons for existing dependencies (Michalski 1997).

Multivariate methods such as cluster analysis (CA), discriminant analysis (DA), principal component analysis (PCA)/factor analysis (FA), and discriminant partial-least squares (DPLS) modeling have been emerging fast as unbiased tools for the analysis and interpretation of the complex datasets (Simeonov et al. 2003, Singh et al. 2004a). These techniques have proven to be efficient methods for analyzing large datasets with complex inter-relationships among the variables and have successfully been applied to various, environmental, chemical, biological, and ecotoxicological case studies (Mujunen et al. 1996; Andren et al. 1998; Palmborg et al. 1998; Singh et al. 2004a, 2005: Sinha et al. 2009). In addition to the two-way approaches, multiway component analysis techniques such as parallel factor analysis (PARAFAC) and Tucker methods have added advantage while dealing with multi-mode data sets.

Here, we report the application of multivariate techniques (CA, DA, PCA/FA, DPLS) to analyze and interpret the chromium-induced oxidative stress and biochemical responses in the plants of $P$. stratiotes, a free floating aquatic macrophyte, known for food and medicinal values. The metal accumulation and induced toxic effects in the plants of $P$. stratiotes have been reported earlier (Sinha et al. 2005). The paper demonstrates as how the multivariate techniques could be successfully employed to extract chemical information from a biological system and to understand the complex relationships among various biochemical variables in the plant tissues.

\section{Materials and methods}

Plant material and experimental setup

The plants of P. stratiotes were obtained from Environmental field laboratory, National Botanical Research
Institute, Lucknow (India) and were grown in acid washed sand in tubs $(75 \mathrm{~cm}$ diameter $\times 30 \mathrm{~cm}$ height $)$ for 2 months. The plants were uprooted and acclimatized in $250 \mathrm{ml}$ beaker containing $200 \mathrm{ml}$ of $10 \%$ Hoagland's solution for 2 weeks under laboratory conditions to obtain healthy plants having well-developed roots. The plants with almost same biomass (2.75-3.25 g fresh weight) were treated (three replicates) with different concentrations $(0,10,40,80,160 \mu \mathrm{M})$ of $\mathrm{Cr}(\mathrm{VI})$ supplied as $\mathrm{K}_{2} \mathrm{Cr}_{2} \mathrm{O}_{7}$ (E. Merck, Germany) prepared in $10 \%$ Hoagland's solution and denoted as $\mathrm{C} 0$ (control), $\mathrm{C} 1, \mathrm{C} 2, \mathrm{C} 3$, and $\mathrm{C} 4$, respectively. All the experiments were performed under standard physiological conditions providing $14 \mathrm{~h}$ per day fluorescent light of $114 \mu \mathrm{mol} \mathrm{m} \mathrm{m}^{-2} \mathrm{~s}^{-1}$ intensity at $26 \pm 2^{\circ} \mathrm{C}$ temperature. The treatment duration was $48 \mathrm{~h}$ (E1), $96 \mathrm{~h}$ (E2) and $144 \mathrm{~h}$ (E3), respectively. After harvesting, these plants were used for the determination of metal accumulation and various biochemical parameters in their roots and shoots separately.

\section{Metal accumulation}

The plants were thoroughly washed with tap and double distilled water. The roots and leaves of the plants were separated manually, dried in an oven at $80^{\circ} \mathrm{C}$ for 1 week. The dried plant tissues were digested in $\mathrm{HNO}_{3}(70 \%)$ using Microwave Digestion System MDS 2000 and Cr content was estimated by GBC Avanta $\sum$ Atomic Absorption Spectrophotometer using air-acetylene gases at $357.9 \mathrm{~nm}$.

\section{Malondialdehyde content}

The level of lipid peroxidation (LPO) in the roots and leaves was measured in terms of malondialdehyde (MDA) content following the method of Heath and Packer (1968).

\section{Estimation of antioxidants}

The plant tissues (200 $\mathrm{mg}$ of roots and leaves) were homogenized in $2 \mathrm{ml}$ of $100 \mathrm{mM}$ potassium phosphate buffer, pH 7.5 containing $1 \mathrm{mM}$ of EDTA and $1 \%(\mathrm{w} / \mathrm{v})$ polyvinylpyrrolidone (PVP). The homogenate was centrifuged at $12,000 \mathrm{rpm}$ for $15 \mathrm{~min}$ at $4^{\circ} \mathrm{C}$. All steps in the preparation of enzyme extract were carried out at $0-4^{\circ} \mathrm{C}$. This supernatant was used to measure the activities of superoxide dismutase, ascorbate peroxidase (APX) and peroxidase.

The activity of superoxide dismutase (SOD) in the roots and leaves of the plant was assayed following the method of Nishikimi and Rao (1972). APX activity was measured in the roots and leaves of the plant by the method of Nakano and Asada (1981). Guaiacol peroxidase (GPX) was measured in the plant parts following the method of Curtis 
(1971), modified by Kato and Shimizu (1987). Carotenoid content from the leaves $(50 \mathrm{mg})$ of the plant was extracted using $80 \%$ chilled acetone and estimated by the method of Duxbury and Yentsch (1956). Free cysteine content in the roots and leaves of the plants (250 mg each) was measured by the method of Gaitonde (1967). Non-protein thiol (NP-SH) content in the roots and leaves (250 mg each) of the plant was measured recording the absorbance at $412 \mathrm{~nm}$ with Ellman's reagent (Ellman 1959). Ascorbic acid content in the roots and leaves (50 mg each) of the plant was estimated by the method of Keller and Schwager (1977).

\section{Chlorophyll and protein contents}

For the estimation of chlorophyll (leaves) and protein (leaves and roots) contents, the blotted fresh parts of the plants were used. Total chlorophyll content in the leaves (100 mg) of the plants was estimated by the method of Arnon (1949). Protein content in the roots and leaves was measured by the method of Lowry et al. (1951).

All the biochemical parameters were estimated spectrophotometrically using a computer controlled pre-calibrated GBC Cintra 10 $\mathrm{e}$ UV-Visible spectrophotometer (Victoria, Australia) equipped with a $1 \mathrm{~cm}$ path length quartz cell.

\section{Multivariate modeling}

The root and shoot datasets used for multivariate modeling were comprised of 9 (Cr-accumulation, MDA, protein, SOD, APX, GPX, ascorbic acid, cysteine, and NP-SH) and 11 (Cr-accumulation, MDA, protein, SOD, APX, GPX, ascorbic acid, cysteine, NP-SH, carotenoids and chlorophyll) variables, respectively. For combined (root and shoot) dataset, nine variables common for both the root and shoot tissues were used. The multivariate data modeling was performed using Statistica 7.0 and N-way toolbox for MATLAB.

Hierarchical agglomerative CA was performed on the normalized data set by means of the Ward's method, using squared Euclidean distances as a measure of similarity. The linkage distance is reported as $D_{\text {link }} / D_{\text {max }}$, which represent the quotient between the linkage distance for a particular case divided by the maximal distance, multiplied by 100 as a way to standardize the linkage distance represented on y-axis (Simeonov et al. 2003; Singh et al. 2004a, 2005).

Principal component analysis/factor analysis attempts to explain the variance of a large set of inter-correlated variables and transforming into a smaller set of independent (uncorrelated) variables (principal components). PCA of the normalized variables was performed to extract significant PCs and to further reduce the contribution of variables with minor significance; these PCs were subjected to varimax rotation generating verifactors (VFs).
DA is used to determine the variables, which discriminate between two or more naturally occurring groups. It constructs a discriminant function (DF) for each group (Singh et al. 2004a, 2005). In the linear discriminant analysis (LDA), the DF is computed (Lambrakis et al. 2004) as;

$\mathrm{DF}=B_{0}+B_{1} X_{1}+B_{2} X_{2}+\cdots+B_{p} X_{p}$

where $X_{1}, X_{2}, \ldots, X_{p}$ are the values of the independent variables, and $B_{0}, B_{1}, \ldots, B_{p}$ are the coefficients estimated from the data.

Discriminant partial least squares (DPLS) analysis aims to find the variables and directions in multivariate space, which discriminate the known classes in calibration set. Here DPLS analysis was performed to clarify difference between the responses of root and shoot tissues against the metal-stress (Singh et al. 2005).

\section{Multi-way component analysis}

Multi-way analysis of data having multi-way structure can provide more in-depth and relevant information for the interpretation of the results (Pardo et al. 2004). The data were arranged in three-way array, $X$, of dimensionality, metal concentrations $\times$ biochemical variables $\times$ exposure durations. Tucker3 model was used for multi-way analysis of the data. The three-way Tucker3 model decomposes the original three-way data array, $\boldsymbol{X}(I \times J \times K)$ in to three loadings matrices, $\mathbf{A}(I \times P), \mathbf{B}(J \times Q)$ and $\mathbf{C}(K \times R)$, as below (Henrion 1994);

$x_{i j k}=\sum_{p=1}^{P} \sum_{q=1}^{Q} \sum_{r=1}^{R} \mathrm{a}_{i p} \cdot \mathrm{b}_{j q} \cdot \mathrm{c}_{k r} \cdot \mathrm{g}_{p q r}+\mathrm{e}_{i j k}$

where $\mathrm{a}_{i p}, \mathrm{~b}_{j q}$, and $\mathrm{c}_{k r}$ are elements of the loadings matrices, $\mathbf{A}, \mathbf{B}$, and $\mathbf{C}$. respectively; $\mathrm{g}_{p q r}$ denotes the elements $(p, q, r)$ of the core array $\mathbf{G}(P \times Q \times R)$, and $\mathrm{e}_{i j k}$ is the error term of the $X$ data array. $P, Q$, and $R$ are the number of factors extracted from the three different modes.

\section{Results and discussion}

The concentration and exposure responses of chromium accumulation in the roots and shoots of the plant of $P$. stratiotes are presented in Tables 1, 2. Variations of the measured biochemical parameters in the roots and shoots of the Cr-exposed plants at different concentrations and durations were evaluated through the Spearman $R$ coefficient as a non-parametric measure of the correlation between $\mathrm{Cr}$-accumulation and biochemical parameters. The results showed that protein $(R=-0.86), \operatorname{SOD}(R=-0.61)$, ascorbic acid $(R=0.64)$, cysteine $(R=-0.80)$, GPX $(R=0.66)$, carotenoid $(R=-0.85)$ and chlorophyll 
Table 1 Accumulation and effect of chromium on biochemical parameters in the root tissues of $P$. stratioites (Sinha et al. (2005))

\begin{tabular}{|c|c|c|c|c|c|c|}
\hline $\begin{array}{l}\text { Chromium } \\
\text { concentration }(\mu \mathrm{M})\end{array}$ & $\begin{array}{l}\text { Exposure } \\
\text { duration }(\mathrm{h})\end{array}$ & Protein (mg/g fw) & MDA $(\mu \mathrm{M} / g)$ & \multicolumn{2}{|c|}{ Cysteine $(\mu \mathrm{M} / \mathrm{g})$} & NP-SH $(\mu \mathrm{M} / g)$ \\
\hline \multirow[t]{3}{*}{0} & 48 & $14.81 \pm 0.26$ & $4.10 \pm 0.38$ & \multicolumn{2}{|c|}{$37.85 \pm 1.94$} & $42.27 \pm 1.87$ \\
\hline & 96 & $14.32 \pm 0.35$ & $4.60 \pm 0.60$ & \multicolumn{2}{|c|}{$38.34 \pm 0.79$} & $44.52 \pm 1.98$ \\
\hline & 144 & $14.63 \pm 0.31$ & $5.20 \pm 1.09$ & \multicolumn{2}{|c|}{$35.83 \pm 0.67$} & $43.56 \pm 0.89$ \\
\hline \multirow[t]{3}{*}{10} & 48 & $15.31 \pm 0.43$ & $6.73 \pm 0.08$ & \multicolumn{2}{|c|}{$43.76 \pm 1.33$} & $42.79 \pm 0.50$ \\
\hline & 96 & $12.67 \pm 0.26$ & $8.51 \pm 0.85$ & \multicolumn{2}{|c|}{$53.73 \pm 2.04$} & $47.52 \pm 1.07$ \\
\hline & 144 & $12.04 \pm 0.42$ & $9.66 \pm 0.68$ & \multicolumn{2}{|c|}{$61.91 \pm 0.56$} & $52.59 \pm 1.46$ \\
\hline \multirow[t]{3}{*}{40} & 48 & $11.53 \pm 0.38$ & $7.77 \pm 0.18$ & \multicolumn{2}{|c|}{$46.98 \pm 1.75$} & $44.82 \pm 1.90$ \\
\hline & 96 & $11.19 \pm 0.16$ & $10.07 \pm 0.49$ & \multicolumn{2}{|c|}{$67.51 \pm 4.64$} & $54.76 \pm 2.10$ \\
\hline & 144 & $10.47 \pm 0.43$ & $6.65 \pm 0.91$ & \multicolumn{2}{|c|}{$60.13 \pm 0.59$} & $66.91 \pm 2.30$ \\
\hline \multirow[t]{3}{*}{80} & 48 & $10.02 \pm 0.49$ & $7.89 \pm 0.76$ & \multicolumn{2}{|c|}{$47.75 \pm 1.21$} & $45.58 \pm 0.55$ \\
\hline & 96 & $10.27 \pm 0.17$ & $7.49 \pm 0.41$ & \multicolumn{2}{|c|}{$60.03 \pm 2.88$} & $63.14 \pm 2.48$ \\
\hline & 144 & $9.20 \pm 0.65$ & $5.79 \pm 0.88$ & \multicolumn{2}{|c|}{$58.68 \pm 0.45$} & $40.12 \pm 1.54$ \\
\hline 160 & 48 & $9.73 \pm 0.62$ & $9.57 \pm 1.54$ & $52.42 \pm$ & & $51.81 \pm 3.19$ \\
\hline & 96 & $8.05 \pm 0.19$ & $6.64 \pm 0.33$ & $59.79 \pm$ & & $44.16 \pm 4.17$ \\
\hline & 144 & $6.46 \pm 0.30$ & $5.48 \pm 0.76$ & $55.75 \pm$ & & $34.69 \pm 1.35$ \\
\hline $\begin{array}{l}\text { Chromium } \\
\text { concentration }(\mu \mathrm{M})\end{array}$ & $\begin{array}{l}\text { Exposure } \\
\text { duration }(\mathrm{h})\end{array}$ & Ascorbic acid $(\mathrm{Mg} / \mathrm{g})$ & SOD (unit/g) & $\operatorname{APX}(\mu \mathrm{M} / \mathrm{min} / \mathrm{g})$ & $\mathrm{Cr}-\mathrm{a}$ & lation $(\mu \mathrm{g} / \mathrm{g} \mathrm{dw})$ \\
\hline 0 & 48 & $138.64 \pm 7.58$ & $36.53 \pm 2.10$ & $188.91 \pm 3.56$ & & \\
\hline & 96 & $142.24 \pm 2.46$ & $34.82 \pm 0.93$ & $198.26 \pm 2.26$ & & \\
\hline & 144 & $128.54 \pm 2.87$ & $34.45 \pm 2.31$ & $210.52 \pm 4.72$ & & \\
\hline 10 & 48 & $157.14 \pm 10.86$ & $36.79 \pm 2.25$ & $219.72 \pm 19.28$ & & 1.31 \\
\hline & 96 & $165.63 \pm 6.39$ & $46.42 \pm 5.01$ & $246.54 \pm 8.55$ & 157 & 16.30 \\
\hline & 144 & $139.86 \pm 4.40$ & $44.67 \pm 0.29$ & $261.11 \pm 29.37$ & 297 & 24.75 \\
\hline 40 & 48 & $158.41 \pm 9.52$ & $33.26 \pm 1.73$ & $272.46 \pm 20.38$ & 134 & 10.94 \\
\hline & 96 & $176.46 \pm 11.25$ & $47.70 \pm 1.86$ & $255.41 \pm 6.41$ & 181 & .39 \\
\hline & 144 & $162.97 \pm 6.38$ & $46.25 \pm 0.13$ & $282.66 \pm 20.04$ & 375 & 22.84 \\
\hline 80 & 48 & $177.38 \pm 8.18$ & $31.70 \pm 1.70$ & $312.45 \pm 22.31$ & 230 & 0.77 \\
\hline & 96 & $162.15 \pm 11.14$ & $47.75 \pm 2.30$ & $301.15 \pm 10.06$ & 243 & 21.37 \\
\hline & 144 & $133.01 \pm 13.17$ & $40.55 \pm 0.64$ & $294.60 \pm 6.10$ & 383 & 26.11 \\
\hline 160 & 48 & $182.91 \pm 6.05$ & $34.59 \pm 3.51$ & $349.92 \pm 6.79$ & 256 & 15.40 \\
\hline & 96 & $131.10 \pm 2.24$ & $44.34 \pm 4.13$ & $245.61 \pm 4.07$ & 665 & 77.39 \\
\hline & 144 & $129.70 \pm 4.79$ & $34.60 \pm 1.35$ & $284.84 \pm 7.97$ & 846 & 27.94 \\
\hline
\end{tabular}

All the values are expressed as mean \pm SD of three replicates

$(R=-0.89)$ in shoots and $\operatorname{APX}(R=0.63)$, cysteine (0.72) and protein $(R=-0.87)$ in the roots were found significantly $(p<0.01)$ correlated with the respective $\mathrm{Cr}$-accumulation. These correlations can be interpreted in view of the established biochemical pathways in the plant systems (Romero-Puertas et al. 2002; Yu et al. 2007) The plant biochemical data were further subjected to different multivariate modeling techniques.

Cluster analysis

Cluster analysis (CA) was performed to identify the root and shoot responses for the $\mathrm{Cr}$-induced oxidative stress in respective tissues on the basis of similarities/dissimilarities in their biochemical responses. CA rendered a dendrogram (Fig. 1), where all the fifteen combinations (concentrations and durations) corresponding to the root and shoot tissues of the plant were fairly grouped into two statistically significant clusters at $\left(D_{\text {link }} / D_{\max }\right) \times 100<60$. The clustering procedure generated two groups (shoots and roots), as the samples within these groups have similar characteristic features and biochemical responses, whereas, dissimilarities between those belonging to the root and shoot tissues. The CA results suggested altogether different responses for the metal-induced stress in root and shoot tissues of the plant. The plants exposed to different $\mathrm{Cr}$ concentrations 
Table 2 Accumulation and effect of chromium on biochemical parameters in the shoot tissues of P. stratioites (Sinha et al. (2005))

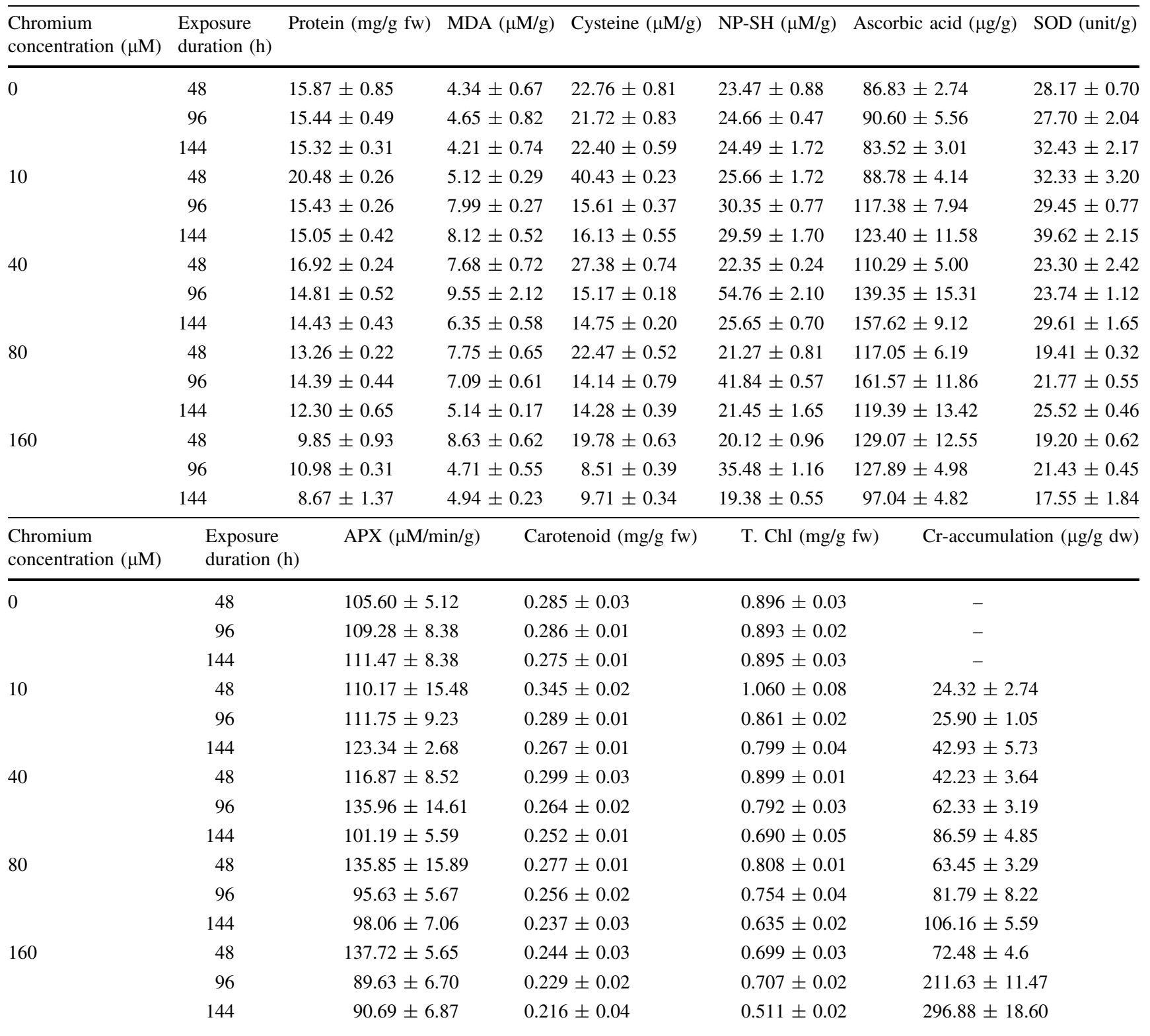

All the values are expressed as mean $\pm \mathrm{SD}$ of three replicates

take up metal through their root system and initially accumulate building up high level in root tissues. It has also been reported that most of the chromium taken up by the plants was retained in the roots (Singh et al. 2004b, c; $\mathrm{Yu}$ and $\mathrm{Gu}$ 2008). Most plants restrict metal transport across the root endodermis (stele), and removing any mobile ions in the xylem by means of storage in cell walls and vacuoles, or binding by the metal-binding proteins such as metallothionines or phytochelatins (MacFarlane and Burchett 2000). A metal concentration gradient, thus build up between the root and shoot tissues of the exposed plants may lead to difference in setting up and magnitude of various biochemical responses in these tissues.
Principal components analysis

PCA/FA was applied to the normalized dataset (combined roots and shoots) with a view to evaluate the plant-metal interactions and differences in induced biochemical responses in root and shoot tissues of the plant of $P$. stratiotes exposed to different concentrations of $\mathrm{Cr}$ and to identify interdependence of the variables and the factors that influence each one. PCA of the combined dataset yielded three significant PCs capturing $79.7 \%$ of the total data variance. The loadings and scores of the first two VFs (VF1 vs.VF2) are presented in Fig. 2. The first two VFs explaining $61.8 \%$ of the total variance (Fig. 2a) reflected 


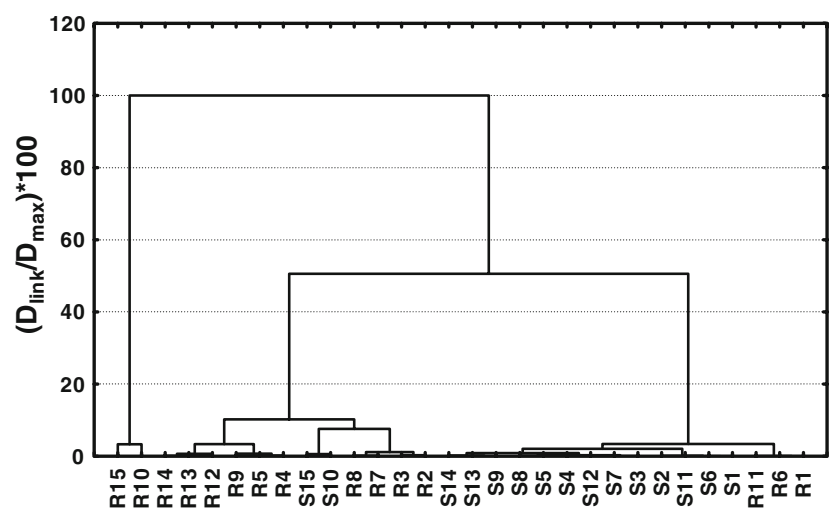

Fig. 1 Dendrogram showing clustering of root and shoot tissue samples of the chromium exposed plants of $P$. stratiotes

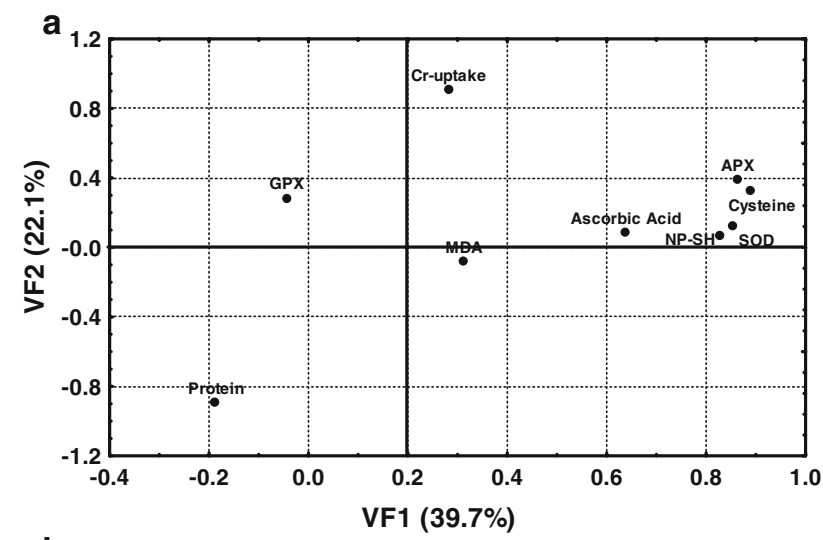

b

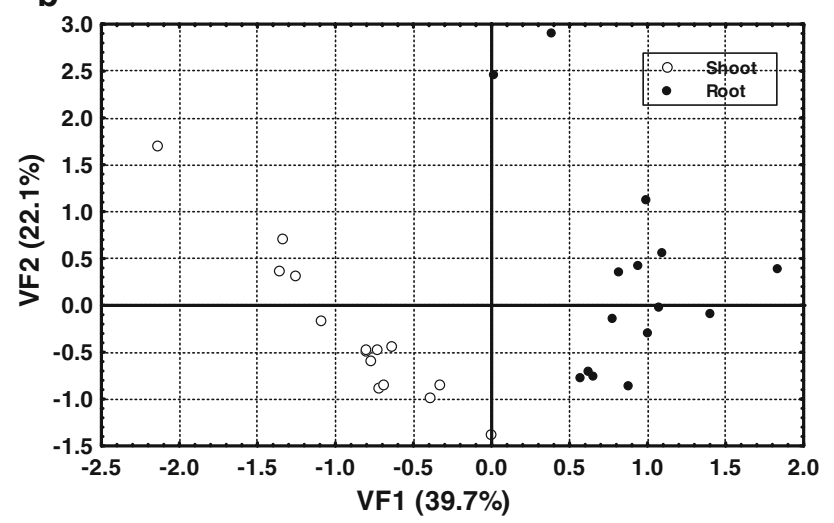

Fig. 2 PCA a loadings and $\mathbf{b}$ scores of the first two VFs obtained for the combined root and shoot dataset of $P$. stratiotes

the main groupings in the data set. The VF1 is largely determined by SOD, cysteine, NP-SH, APX and ascorbic acid with strong positive loadings, grouping in the upper right quadrant, whereas, in VF2, Cr-accumulation alone showed high positive loading. A close association of SOD, cysteine, NP-SH, APX and ascorbic acid in first VF can be explained as the $\mathrm{Cr}$-induced oxidative stress enhances generation of the ROS in the plant and the defense mechanism of the plant under stress conditions, utilizes SOD, a protective antioxidant enzyme located in various cell compartments to catalyze the disproportionation of ${ }^{\circ} \mathrm{O}_{2}{ }^{-}$to $\mathrm{H}_{2} \mathrm{O}_{2}$ and $\mathrm{O}_{2}$ molecules. Simultaneously, the stressed plant cells enhance synthesis of antioxidant compounds (ascorbic acid, cysteine, NP-SH) to counter with the induced stress situation. The NP-SH binds with the metal ions and helps to reduce toxicity. Ascorbic acid which is found at high concentrations in chloroplast and other cellular compartments is crucial for plant defense against oxidative stress (Noctor and Foyer 1998). Ascorbic acid serves as a substrate for APX, a key enzyme of the ascorbate cycle and is converted to dehydroascorbate (DHA) during elimination of peroxides. It is generally believed that maintaining a high reduced per oxidized ratio of ascorbic acid is essential for the proper scavenging of ROS in the cells. This ratio is maintained by monodehydro-ascorbaie reductase (MDAR) and dehydroascorbate reductase (DHAR) which participates in lignin biosynthesis building up a physical barrier against heavy metal poisoning.

The scores plot (Fig. 2b) also suggested a visible differentiation between the root and shoot tissue responses grouping them in two visible clusters. It may be noted that the root tissues differentiated prominently in terms of MDA, SOD, APX, NP-SH, cysteine, ascorbic acid and Craccumulation, whereas, response in shoot tissues was more prominent in terms of protein and GPX. This reflects pattern of variation and difference in responses of root and shoot tissues of the plant in terms of dominance of the biochemical variables at all concentrations and durations. A similar trend and pattern of changes for these biochemical variables induced in the roots and shoots of the $P$. stratiotes exposed to $\mathrm{Cr}$ have been reported earlier (Sinha et al. 2005).

Further, the differences between the responses of root and shoot tissues of the plant exposed to different concentrations of $\mathrm{Cr}$ were investigated through PCA/FA applied to the datasets of the root and shoot tissues, separately. PCA of the root data set yielded three PCs capturing $85.5 \%$ of the total variance. VF1 is largely determined by SOD, GPX, cysteine and NP-SH having strong positive loadings. This factor is thus, mainly comprised of variables that generally take part in defense mechanism of the plant under stress and may be termed as 'antioxidant factor'. The protective antioxidant enzymes viz. SOD and GPX located in various cell compartments catalyze the disproportionation of ${ }^{\circ} \mathrm{O}_{2}{ }^{-}$to $\mathrm{H}_{2} \mathrm{O}_{2}$ and $\mathrm{O}_{2}$. SOD and GPX in general show simultaneous induction and decline, which may be due to their co-regulation (Shigeoka et al. 2002). On the other hand, VF2 has strong positive loadings on APX, cysteine and $\mathrm{Cr}$-accumulation and strong negative loadings on protein alone. Correlated variables in this factor are mainly indicator of plant stress and hence, this factor may be termed as 'stress factor'. Chromium accumulation is 
known to create metal stress conditions in the plant. This is reflected in terms of increased level of anti-oxidants in the plant. The third factor exhibited high positive loadings on APX, MDA and ascorbic acid.

A simultaneous interpretation of the scores and loadings suggested that no remarkable changes could be observed in terms of biochemical variables in the plants at low concentrations and durations. Moderate and higher concentrations and longer exposure periods (E2, E3), however, brought significant induction of antioxidant biochemical variables. At higher concentrations and longer exposure periods, the plants experienced higher stress conditions exhibiting remarkable changes in lipid peroxidation as indicated by the anti-oxidant compounds/activities and MDA content. Such a behavior may be due to higher toxicity in the plants creating almost plant death conditions.

PCA/FA performed on shoot dataset also yielded three significant PCs explaining about $84.7 \%$ of data variance. The VF1 (46.8\%) showed high positive loadings on SOD, cysteine, carotenoid, chlorophyll and protein and high negative loadings on Cr-accumulation. VF2 exhibited high positive loadings on MDA and APX. The inverse relationship between the Cr-accumulation and cysteine, protein, carotenoids, chlorophyll and SOD can be explained in terms of negative influence of increasing metal accumulation on these variables. A reduction in SOD activity may be attributed to inactivation of enzyme by $\mathrm{H}_{2} \mathrm{O}_{2}$, which is produced in different cellular compartments and also from a member of non-enzymatic and enzymatic processes in the cells (Sandalio et al. 2001). In contrast, Yu et al. (2007) reported that at low $\mathrm{Cr}(\mathrm{VI})$ concentration $\left(1.05 \mathrm{mg} \mathrm{Cr}^{-1}\right)$, activity of SOD was slightly decreased compared to control, whereas, with increasing $\mathrm{Cr}$ addition, SOD activity gradually increased to the level of control in hybrid willow. The reduced chlorophyll content of leaves is a characteristic symptom of metal toxicity (Hegedus et al. 2001). Yu et al. (2007) reported no significant difference in chlorophyll $a$ and $b$ contents in hybrid willow exposed to high $\mathrm{Cr}(\mathrm{VI})$ concentrations $\left(2.10-12.60 \mathrm{mg}^{-1}\right)$ as compared to the control. This may be explained by the inhibition of different stages of chlorophyll biosynthesis (Parekh et al. 1990). The decrease in cysteine content in the leaves may be due to decreased activities of sulphate reduction enzymes, ATP sulphurylase and adenosine 5-phosphosulphate sulphotransferase under metal stress (Nussbaum et al. 1988). Higher levels of $\mathrm{Cr}$ result in decreasing biosynthesis of protein in the plant tissue ( $\mathrm{Yu}$ and $\mathrm{Gu}$ 2007). The third factor (VF3) capturing $18.2 \%$ of the variance, had strong positive loadings on ascorbic acid and NP-SH.

The distribution pattern of scores along with the loadings (Figure not shown for brevity) suggested that the protein content and SOD in the plant tissues are influenced at low metal concentrations and short exposure periods.
However, low concentrations with higher exposure periods may bring changes in biochemical responses as well. Both the moderate to higher metal concentrations and exposure periods, however, result in significant changes in GPX activity of the shoot tissues. It may further be noted that higher concentrations of metal even at relatively shorter exposure durations could influence the MDA and ascorbic acid contents and APX activity.

\section{Discriminant analysis}

Variations in plant response to Cr-induced stress in terms of biochemical parameters measured in the root and shoot tissues of the macrophyte were further evaluated through discriminant analysis (DA). Linear DA was performed on raw data after dividing the whole data set into two groups (roots and shoots). Discriminant functions (DFs) obtained from the standard, forward stepwise and backward stepwise modes of DA are shown in Table 3. The standard, forward and backward stepwise DA modes constructed DFs including all 9, 5 and 1 parameter, respectively, and rendered the corresponding CMs assigning $100 \%$ cases correctly. Forward stepwise DA showed that APX, MDA, SOD, ascorbic acid and cysteine are followed by a single variable (APX) in the backward stepwise DA with same number of correct assignations. Thus, the DA results suggest that APX is the most significant parameter to discriminate between the two different plant tissues (roots and shoots) exposed to chromium, which means that this parameter accounts for most of the expected variations in the biochemical parameters (Table 3). Further, a relative influence of each variable in the DF was determined through the 'standardized discrimination coefficient' (SDC) computed from the values of the coefficients of the DFs $\left(B_{1}\right.$, $B_{2}, \ldots, B_{p}$ ) multiplied with the 'pooled standard deviations'. Consequently, it is obvious that APX and cysteine are the most significance variables in the DFs, which means they have the principal role in the classification of the two clusters analysis groups. Both CA and DA predict important differences in responses of root and shoot tissues in terms of induced biochemical changes in the plant exposed to chromium. DA shows that there are significant differences between the root and shoot responses, that are expressed in terms of single discriminating variable (APX).

The influence of chromium concentration on the plants of $P$. stratiotes was studied through DA performed on measured variables. The category variables $(Y)$ were the five different concentrations of chromium to which the plants were exposed. The DFs obtained from the standard, forward stepwise and backward stepwise modes of DA are shown in Table 4. The standard and forward stepwise DA modes constructed DFs including all nine and seven parameter, respectively, and rendered the corresponding 
Table 3 Classification functions for discriminant analysis of variation between the root-shoot samples of the exposed plants of $P$. stratiotes

\begin{tabular}{|c|c|c|c|c|c|}
\hline \multicolumn{6}{|c|}{ Linear Discriminant Functions for Groups } \\
\hline & \multicolumn{5}{|c|}{ Coefficient $^{\mathrm{a}}$} \\
\hline & Root & Shoot & $\mathrm{Bx}$ & Pooled SD & SDC \\
\hline \multicolumn{6}{|l|}{ Standard mode } \\
\hline APX & 0.47 & 0.35 & 0.12 & 83.20 & 10.18 \\
\hline Ascorbic acid & 0.61 & 0.40 & 0.20 & 28.13 & 5.72 \\
\hline Cysteine & -0.63 & -1.19 & 0.56 & 18.93 & 10.66 \\
\hline GPX & 0.14 & 0.21 & -0.07 & 30.97 & -2.05 \\
\hline MDA & -4.49 & -0.67 & -3.82 & 1.82 & -6.96 \\
\hline Protein & 8.62 & 9.78 & -1.16 & 3.08 & -3.56 \\
\hline NP-SH & -0.44 & -0.59 & 0.15 & 13.50 & 2.04 \\
\hline SOD & 0.77 & 0.46 & 0.31 & 9.06 & 2.83 \\
\hline Cr-accumulation & 0.09 & 0.11 & -0.02 & 198.99 & -3.81 \\
\hline Constant & -146.09 & -107.95 & & & \\
\hline \multicolumn{6}{|c|}{ Forward stepwise mode } \\
\hline APX & 0.23 & 0.08 & 0.15 & 83.20 & 12.31 \\
\hline MDA & -5.00 & -1.45 & -3.55 & 1.82 & -6.47 \\
\hline SOD & 1.16 & 0.89 & 0.27 & 9.06 & 2.48 \\
\hline Ascorbic acid & 0.51 & 0.30 & 0.22 & 28.13 & 6.05 \\
\hline Cysteine & 0.32 & -0.04 & 0.35 & 18.93 & 6.67 \\
\hline Constant & -83.27 & -29.15 & & & \\
\hline \multicolumn{6}{|c|}{ Backward stepwise mode } \\
\hline APX & 0.23 & 0.098 & 0.13 & 83.20 & 10.97 \\
\hline Constant & -30.77 & -6.16 & & & \\
\hline
\end{tabular}

${ }^{a}$ Discriminant function coefficient for root and shoot samples

CMs assigning 90 and $93.3 \%$ cases correctly. Thus, the DA results suggest that except cysteine and NP-SH, all other seven variables are significant parameters to discriminate between the five sets of the plant responses corresponding to different chromium concentrations.

The effect of chromium exposure duration in the plants of $P$. stratiotes was studied through DA performed on measured variables with three different exposure durations (E1, E2 and E3) being the category variables $(Y)$. The DFs obtained from the DA are shown in Table 5. The standard and forward stepwise DA modes constructed DFs including all nine and seven parameters (except ascorbic acid and MDA), respectively, and rendered the corresponding CMs assigning $83.3 \%$ cases correctly. Thus, the DA results suggest that seven variables are significant parameters to discriminate between the three sets of plant responses corresponding to different exposure durations.

Discriminant partial-least squares analysis

Differences in responses of the root and shoot tissues of the chromium-exposed plants were also studied through DPLS.
Table 4 Classification functions for discriminant analysis of chromium concentrations

\begin{tabular}{|c|c|c|c|c|c|}
\hline & \multicolumn{5}{|c|}{ Linear Discriminant Functions for Groups } \\
\hline & \multicolumn{5}{|c|}{ Coefficient $^{\mathrm{a}}$} \\
\hline & $\mathrm{C} 0$ & $\mathrm{C} 1$ & $\mathrm{C} 2$ & $\mathrm{C} 3$ & $\mathrm{C} 4$ \\
\hline \multicolumn{6}{|l|}{ Standard mode } \\
\hline APX & 0.10 & 0.03 & 0.03 & 0.10 & 0.12 \\
\hline Ascorbic acid & 0.32 & 0.42 & 0.48 & 0.47 & 0.50 \\
\hline Cysteine & -1.44 & -1.49 & -1.30 & -1.33 & -1.30 \\
\hline GPX & -0.28 & -0.36 & -0.26 & -0.15 & -0.06 \\
\hline MDA & 7.89 & 11.54 & 10.56 & 8.66 & 8.47 \\
\hline Protein & 15.84 & 17.53 & 15.97 & 14.70 & 13.49 \\
\hline NP-SH & -0.64 & -0.79 & -0.71 & -0.78 & -0.82 \\
\hline SOD & 4.31 & 4.95 & 3.87 & 3.13 & 2.36 \\
\hline Cr-accumulation & 0.09 & 0.12 & 0.12 & 0.12 & 0.15 \\
\hline Constant & -194.52 & -255.63 & -214.29 & -176.97 & -158.50 \\
\hline \multicolumn{6}{|c|}{ Forward stepwise mode } \\
\hline Protein & 12.79 & 14.26 & 13.12 & 11.75 & 10.55 \\
\hline SOD & 2.99 & 3.54 & 2.65 & 1.86 & 1.10 \\
\hline MDA & 7.13 & 10.67 & 9.79 & 7.84 & 7.64 \\
\hline Cr-uptake & 0.05 & 0.08 & 0.09 & 0.09 & 0.11 \\
\hline GPX & -0.34 & -0.42 & -0.32 & -0.21 & -0.12 \\
\hline APX & -0.18 & -0.26 & -0.23 & -0.17 & -0.15 \\
\hline Ascorbic acid & 0.33 & 0.40 & 0.46 & 0.44 & 0.45 \\
\hline Constant & -158.34 & -212.85 & -181.37 & -140.97 & -122.04 \\
\hline
\end{tabular}

${ }^{a}$ Discriminant function coefficient for different concentrations of chromium

The loadings and scores plots of first two latent variables (LVs) are presented in Fig. 3. The scores plots show clear cut groupings of the root and shoot samples (Fig. 3a), whereas, distribution pattern of response variables pertaining to two groups of samples are displayed in the corresponding loadings plot (Fig. 3b). Mainly SOD, cysteine, APX, NP-SH, ascorbic acid, MDA, GPX, and chromiumaccumulation dominated the root samples, whereas, the shoot samples were dominated by protein alone. The observed differences between the responses of root and shoot tissues to the chromium-induced stress as described by DPLS are in accordance with the expected lines.

Multi-way component analysis

Simultaneous influence of the chromium concentrations and exposure durations on biochemical changes in root and shoot tissues of the plant was studied through the multiway component analysis of the data. The three-way data comprised of metal concentrations, biochemical variables and exposure durations was modeled using the Tucker3 
Table 5 Classification functions for discriminant analysis of exposure time

\begin{tabular}{lrrr}
\hline Variable & \multicolumn{3}{l}{ Standard mode } \\
\cline { 2 - 4 } & \multicolumn{2}{l}{ Coefficient $^{\mathrm{a}}$} & \\
\cline { 2 - 4 } & \multicolumn{2}{c}{ E1 } & \\
\hline APX & 0.37 & 0.31 & 0.32 \\
Ascorbic acid & 0.40 & 0.37 & 0.36 \\
Cysteine & -0.89 & -1.03 & -1.16 \\
GPX & 0.32 & 0.35 & 0.26 \\
MDA & 0.14 & 0.08 & 0.17 \\
Protein & 11.48 & 10.77 & 10.20 \\
NP-SH & -0.76 & -0.43 & -0.60 \\
SOD & -0.76 & -0.36 & 0.04 \\
Cr-accumulation & 0.10 & 0.10 & 0.10 \\
Constant & -116.76 & -114.42 & -104.17 \\
Forward stepwise & & & \\
GPX & 0.35 & 0.38 & 0.29 \\
Cr-uptake & 0.09 & 0.09 & 0.09 \\
NP-SH & -0.25 & 0.03 & -0.14 \\
APX & 0.45 & 0.39 & 0.39 \\
SOD & -0.67 & -0.27 & 0.12 \\
Protein & 10.60 & 9.94 & 9.40 \\
Cysteine & -1.18 & -1.31 & -1.43 \\
Constant & -95.79 & -96.43 & -87.16 \\
Backward & & &
\end{tabular}

Backward stepwise mode

No variables in the model

${ }^{a}$ Discriminant function coefficient for different exposure time

model. Finally, the Tucker model of complexity, $(3,3,1)$, that is three components each in first (concentrations) and second (biochemical variables) modes and single component in third mode (exposures) was selected, which captured $70 \%$ of the data variance. The loadings of metal concentrations mode (A), biochemical parameters (B) and exposure durations $(\mathrm{C})$ are displayed in Fig. $4 \mathrm{a}-\mathrm{c}$.

The information relating to the metal concentrations is described in terms of loadings of each sample on the three components of matrix A (Fig. 4a). The first component (A1) has high positive loadings on metal concentrations $\mathrm{C} 0-\mathrm{C} 4$ corresponding to the shoot samples and high negative loadings on concentrations $\mathrm{C} 1-\mathrm{C} 4$ in root samples. The second component (A2) has high positive loadings on $\mathrm{C} 0$ and $\mathrm{C} 1$ in root and $\mathrm{C} 1$ in shoot samples and high negative loadings on $\mathrm{C} 4$ in both the root and shoot samples. The third component (A3) has high positive loadings on C0 in both the root and shoot samples and negative loadings on $\mathrm{C} 2$ and $\mathrm{C} 3$ in shoot samples.

The loadings of each biochemical variables on the three components of matrix $\mathbf{B}$ are shown in Fig. $4 \mathrm{~b}$. The first component (B1) has high positive loadings on APX, ascorbic
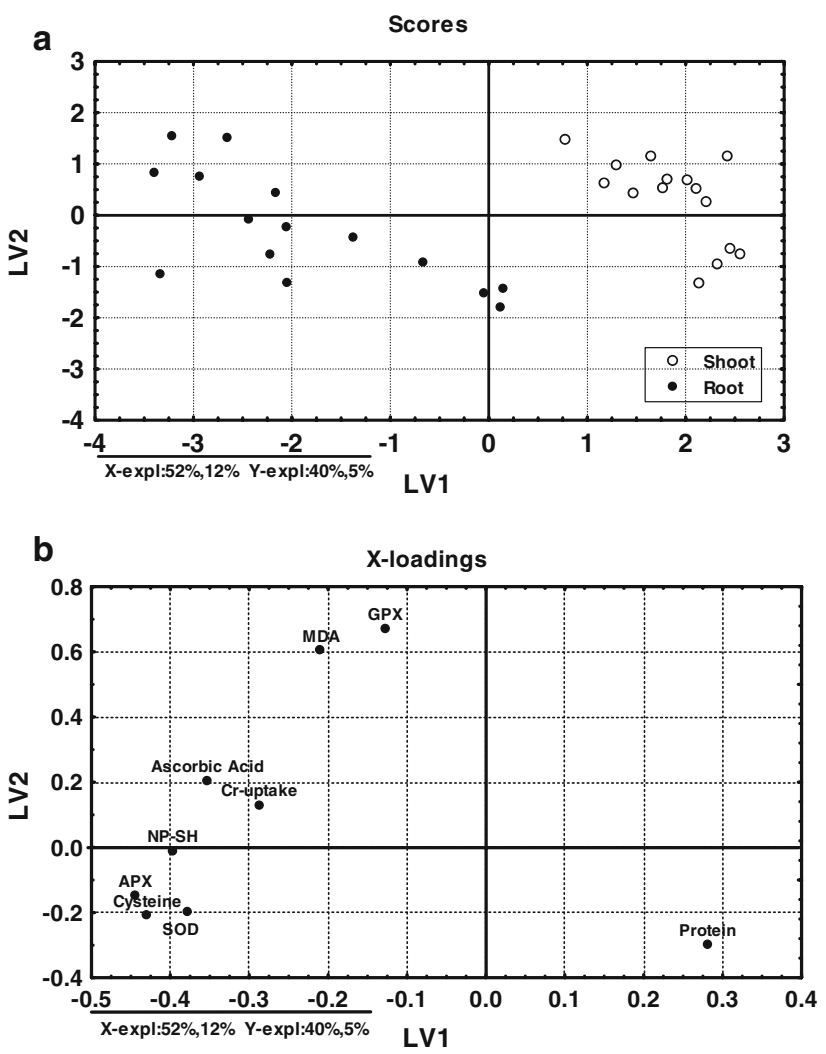

Fig. 3 DPLS a scores and b loadings of the first two LVs obtained for the root and shoot tissues of $P$. stratiotes

acid, cysteine, NP-SH, SOD, MDA and Cr-accumulation and negative loadings on protein alone. In second component (B2), protein, NP-SH, and SOD have high negative loadings, whereas, GPX and Cr-accumulation exhibited high positive loadings. In third component (B3), APX, cysteine and SOD have high positive, whereas, MDA and ascorbic acid have high negative loadings. The single component of exposure mode (C) exhibited high positive loadings on all the three exposure durations, which have increasing trend from shorter (E1) to longer (E3) durations (Fig. 4c).

The core array, $\mathrm{G}$ of the model with dimensions, $3 \times 3 \times 1$, is displayed in Table 6 . The core element $\mathrm{g}_{p q r}$ reflects the extent of the interaction between $\mathrm{Ap}, \mathrm{Bq}$, and $\mathrm{Cr}(p=1,2,3 ; q=1,2,3 ; r=1)$. The sign of $\mathrm{g}_{p q r}$ is determined by the signs of $\mathrm{Ap}, \mathrm{Bq}$, and $\mathrm{Cr}$. Since $\mathrm{Cr}$ is always positive, we will focus on the signs of other two matrices, Ap and Bq. Analysis of the elements reveals that $100 \%$ of the variability of the core is explained by the three elements, $(1,1,1),(2,2,1)$ and $(3,3,1)$. The first core element $(1,1,1)$ with a negative value $(-11.26)$ explains $73.13 \%$ of the core variance and reflects the interactions between the first factors in each of the modes (A1, B1, and C1). Since, all the loadings on exposure mode (C) are positive, the signs of the other two modes (A and B) determine the sign of first core element (Henrion 1994; Stanimirova and 

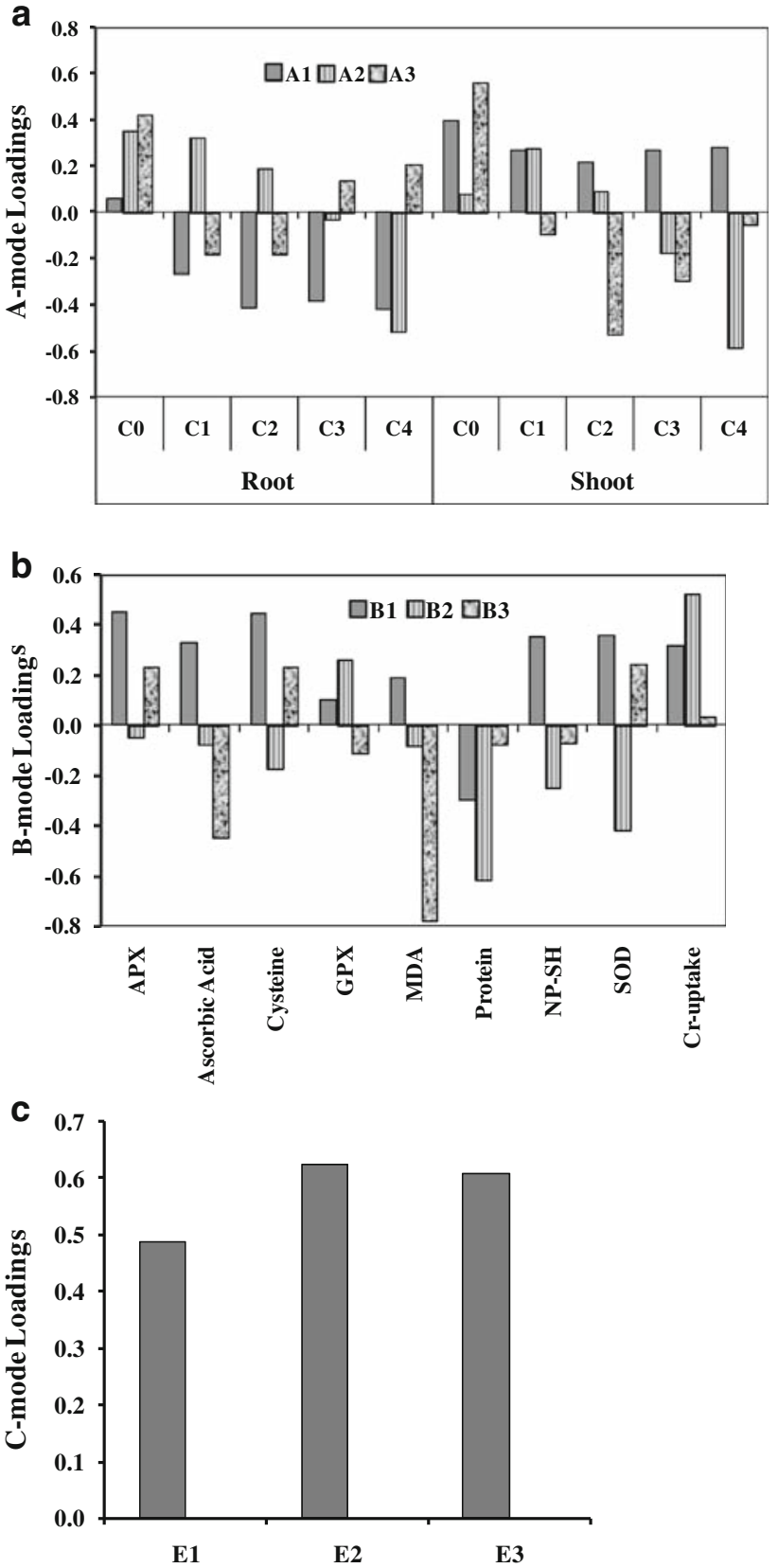

Fig. 4 Plot of loadings values for the components extracted by Tucker3 model applied to the $P$. stratiotes data set for a metal concentrations (A1, A2, A3), b biochemical variables (B1, B2, B3), and $\mathbf{c}$ exposure time $(\mathrm{C})$ mode

Table 6 Core array $(\mathrm{G})$ of the Tucker $(3,3,1)$ model in the unfolded form

\begin{tabular}{llll}
\hline & C1 & C1 & C1 \\
& B1 & B2 & B3 \\
\hline A1 & $-11.26(73.13 \%)$ & 0.00 & 0.00 \\
A2 & 0.00 & $-5.60(18.10 \%)$ & 0.00 \\
A3 & 0.00 & 0.00 & $3.90(8.78 \%)$ \\
\hline
\end{tabular}

Values in parentheses denote percent variance
Simeonov 2005). Hence, this element can be explained through considering interactions between high positive loadings of $\mathrm{A} 1$ and high negative loadings of $\mathrm{B} 1$ or vice versa (Fig. 4a,b). From the first combination, it is revealed that at all the metal concentrations; protein content in shoot samples is most influenced at all the exposure durations. The second combination suggests significant changes in the biochemical variables (APX, ascorbic acid, cysteine, NP$\mathrm{SH}, \mathrm{SOD}, \mathrm{MDA}$ ) in root tissues with metal accumulation throughout the exposure.

The second core element $(2,2,1)$ of $G$ with a negative value $(-5.6)$ explained $18.10 \%$ core variance. It can be explained by interactions among the A2, B2 and C components. Like the first core element, this may also be explained by considering negative loadings in A2 and positive ones in $\mathrm{B} 2$ or vice versa along with the positive loadings of $\mathrm{C}$ component. The first combination suggests that at highest metal concentration, GPX, both in root and shoot tissues is most influenced with Cr-accumulation. The second combination reveals that even at lowest metal concentration, protein, NP-SH and SOD are significantly affected in both the plant tissues.

The third core element $(3,3,1)$ of $\mathrm{G}$ with a positive value (3.90) explained $8.78 \%$ core variance. The interactions among the $\mathrm{A} 3$ and $\mathrm{B} 3$ components with $\mathrm{C}$ suggest that MDA and ascorbic acid are the most influenced variables in shoot samples even at moderate metal concentrations during all the exposures.

\section{Conclusions}

Multivariate modeling (CA, DA, PCA/FA, DPLS, threeway analysis) was performed to investigate the chromiuminduced oxidative stress and subsequent biochemical changes measured in the plants of $P$. stratiotes. The modeling techniques provided information on differential pattern for the onset and magnitude of the oxidative stress induced in the root and shoot tissues of the exposed plants as a function of chromium concentration and exposure time. Multivariate analysis identified the significant biochemical variables responsible for the discrimination between the root and shoot tissues, and those of relatively higher significance as induced in the plant under the stress conditions. The multivariate approaches, thus, allowed for the extraction of information from the data on the patterns of variation in induced biochemical responses and their inter-relationships in the metal exposed plants. This study shows that application of the multivariate modeling techniques to the complex biochemical datasets obtained through plant nutrition and phyto-remediation research can facilitate the interpretation and visualization of the interrelationships of the variables. 
Acknowledgments The authors would like to thank the Director, National Botanical Research Institute, Lucknow for encouragement. Suggestions provided by Prof. V. Simeonov (Faculty of Chemistry, University of Sofia, Bulgaria) in multivariate analysis of data are gratefully acknowledged.

Open Access This article is distributed under the terms of the Creative Commons Attribution Noncommercial License which permits any noncommercial use, distribution, and reproduction in any medium, provided the original author(s) and source are credited.

\section{References}

Andren C, Eklund B, Gravefors E, Kukulska Z, Tarkpea M (1998) A multivariate biological and chemical characterization of industrial effluents connected to municipal sewage treatment plants. Environ Toxicol Chem 17:228-233. doi:10.1897/1551-5028 (1998)017<0228:AMBACC >2.3.CO;2

Arnon DI (1949) Copper enzymes in isolated chloroplasts polyphenoloxidase in Beta vulgaris. Plant Physiol 24:1-15. doi:10.1104/ pp.24.1.1

Curtis CR (1971) Disc electrophoretic comparison of proteins and peroxidases from Phaseolus vulgaris infected with Agrobacterium tumefaciens. Can J Bot 49:333-337. doi:10.1139/b71-056

Duxbury AC, Yentsch CS (1956) Plankton pigment monograph. J Mar Res 15:92-101

Ellman GL (1959) Tissue sulfhydryl groups. Arch Biochem Biophys 82:70-77. doi:10.1016/0003-9861(59)90090-6

Foyer CH, Nocter G (2003) Redox sensing and signalling associated with reactive oxygen in chloroplasts, peroxisomes and mitochondria. Physiol Plant 119:355-364. doi:10.1034/j.1399-3054. 2003.00223.x

Gaitonde MK (1967) A spectrophotometric method for the direct determination of cysteine in the presence of other naturally occurring amino acids. Biochem J 104:627-633

Heath RL, Packer L (1968) Photoperoxidation in isolated chloroplast. I. Kinetics and stoichiometry of fatty acid peroxidation. Arch Biochem Biophys 125:189-198. doi:10.1016/0003-9861(68)90 654-1

Hegedus A, Erdei S, Horvath G (2001) Comparative studies of $\mathrm{H}_{2} \mathrm{O}_{2}$ detoxifying enzymes in green and greening barley seedlings under cadmium stress. Plant Sci 160:1085-1093. doi:10.1016/ S0168-9452(01)00330-2

Henrion R (1994) $N$-way principal component analysis theory, algorithms and applications. Chemoetr Intell Lab Syst 25:1-23. doi:10.1016/0169-7439(93)E0086-J

Kato M, Shimizu S (1987) Chlorophyll metabolism in higher plants. VII. Chlorophyll degradation in senescing tobacco leaves; phenolic dependent peroxidative degradation. Can J Bot 65: 729-735. doi:10.1139/b87-097

Keller T, Schwager H (1977) Air pollution and ascorbic acid. Eur J For Pathol 7:338-350. doi:10.1111/j.1439-0329.1977.tb00603.x

Kimbrough DE, Cohen Y, Winer AM, Creelman L, Mabuni C (1999) A critical assessment of chromium in the environment. Crit Rev Environ Sci Technol 29:1-46. doi:10.1080/10643389991259164

Lambrakis N, Antonakos A, Panagopoulos G (2004) The use of multicomponent statistical análisis in hydrogeological environmental research. Water Res 38:1862-1872. doi:10.1016/j.watres. 2004.01.009

Larson RA (1988) The antioxidants of higher plants. Phytochemistry 27:969-978. doi:10.1016/0031-9422(88)80254-1

Lowry OH, Rosebrought NJ, Farr AL, Randall RJ (1951) Protein measurement with folin-phenol reagent. Biol Chem 193:265-275
MacFarlane GR, Burchett MD (2000) Cellular distribution of copper, lead and zinc in the grey mangrove Avicennia marina (Forsk.) Vierh. Aquat Bot 68:45-59. doi:10.1016/S0304-3770(00)00105-4

Mazhoudi S, Chaoui A, Ghorbal MH, Ferjani EE (1997) Response of antioxidant enzymes to excess copper in tomato (Lycopersicon esculentum, Mill.). Plant Sci 127:129-137. doi:10.1016/S01689452(97)00116-7

Michalski RS, Kaufman KA (1997) Sixth international conference on Intelligent Information Systems, Zakopane, Poland, June, 1997

Mujunen SP, Minkkinen P, Holmbom B, Oikari A (1996) PCA and PLS methods applied to ecotoxicological data: ecobalance project. J Chemometr 10:411-424. doi:10.1002/(SICI)1099-128 X(199609)10:5/6<411::AID-CEM441>3.0.CO;2-7

Nakano Y, Asada K (1981) Hydrogen peroxide is scavenged by ascorbate-specific peroxidase in spinach chloroplasts. Plant Cell Physiol 22:867-880

Nishikimi M, Rao NA (1972) The occurrence of superoxide anion in the reaction of reduced phenazine methosulphate and molecular oxygen. Biochem Biophys Res Commun 48:849-854. doi: 10.1016/S0006-291X(72)80218-3

Noctor G, Foyer CH (1998) Ascorbate and glutathione: keeping active oxygen under control. Annu Rev Plant Physiol Plant Mol Biol 49:249-279. doi:10.1146/annurev.arplant.49.1.249

Nussbaum S, Schumtz D, Brunold C (1988) Regulation of assimilatory sulphate reduction by cadmium in Zea mays L. Plant Physiol 88:1407-1410. doi:10.1104/pp.88.4.1407

Palmborg C, Bringmark L, Bringmark A, Nordgern A (1998) Multivariate analysis of microbial activity and soil organic matter at a forest site subjected to low-level heavy metal contamination. Ambio 27:53-57

Pardo R, Helena BA, Cazurro C, Guerra C, Debán L, Guerra CM, Vega M (2004) Application of two- and three-way principal component analysis to the interpretation of chemical fractionation results obtained by the use of the B.C.R. procedure. Anal Chim Acta 523:125-132. doi:10.1016/j.aca.2004.07.015

Parekh D, Puranik RM, Srivastava HS (1990) Inhibition of chlorophyll biosynthesis by cadmium in greening maize leaf segments. Biochem Biophys Pflanzen 186:239-242

Romero-Puertas MC, Palma JM, Gomez M, del Rio A, Sandalio LM (2002) Cadmium causes the oxidative modification of proteins in pea plants. Plant Cell Environ 25:677-686. doi:10.1046/j.13653040.2002.00850.x

Sandalio LM, Dalurzo HC, Gomez M, Romero-Puertas MC, del Rio LA (2001) Cadmium induces changes in the growth and oxidative metabolism of pea plants. J Exp Bot 52:2115-2126

Schutzendubel A, Nikolova P, Rudolf C, Polle A (2002) Cadmium and $\mathrm{H}_{2} \mathrm{O}_{2}$ induced oxidative stress in Populus canescens roots. Plant Physiol Biochem 40:577-584. doi:10.1016/S0981-9428 (02)01411-0

Shigeoka S, Ishikawa I, Tamoi M, Miyagawa Y, Takeda T, Yabuta Y, Yoshimura K (2002) Regulation and function of ascorbate peroxidise isoenzymes. J Exp Bot 53:1305-1319. doi:10.1093/ jexbot/53.372.1305

Simeonov V, Stratis JA, Samara C, Zachariadis G, Voutsa D, Anthemidis A, Sofoniou M, Kouimtzis T (2003) Assessment of the surface water quality in Northern Greece. Water Res 37:4119-4124. doi:10.1016/S0043-1354(03)00398-1

Singh KP, Malik A, Mohan D, Sinha S (2004a) Multivariate statistical techniques for evaluation of spatial and temporal variations in water quality of Gomti River (India)-A case study. Water Res 38:3980-3992. doi:10.1016/j.watres.2004.06.011

Singh S, Saxena R, Pandey K, Bhatt K, Sinha S (2004b) Translocation of metals and its effects in the plant of tomato grown on various amendment of tannery wastes: evidence for involvement of antioxidants. Chemosphere 57:91-99. doi:10.1016/j.chemosp here.2004.04.041 
Singh S, Saxena R, Pandey K, Bhatt K, Sinha S (2004c) Response of antioxidants in Helianthus annuus $\mathrm{L}$. grown on different amendments of tannery sludge: Its metal accumulation potential. Chemos 57:1663-1673. doi:10.1016/j.chemosphere.2004.07.049

Singh KP, Malik A, Mohan D, Sinha S, Singh VK (2005) Chemometric data analysis of pollutants in wastewater-A case study. Anal Chim Acta 532:15-25. doi:10.1016/j.aca.2004.10. 043

Sinha S, Saxena R, Singh S (2005) Chromium induced lipid peroxidation in the plants of Pistia stratiotes L.: role of antioxidants and antioxidant enzymes. Chemos 58:595-604. doi: 10.1016/j.chemosphere.2004.08.071

Sinha S, Gupta AK, Bhatt K, Pandey K, Rai UN, Singh KP (2006) Distribution of metals in the edible plants grown at Jajmau, Kanpur (India) receiving treated tannery wastewater: relation with physico-chemical properties of soil. Environ Monit Assess 115:1-22. doi:10.1007/s10661-006-5036-z

Sinha S, Basant A, Malik A, Singh KP (2009) Iron-induced oxidative stress in a macrophyte: a chemometric approach. Ecotoxicol Environ Saf 72:585-595. doi:10.1016/j.ecoenv.2008.04.017
Stanimirova I, Simeonov V (2005) Modeling of environmental fourway data from air quality control. Chemom Intell Lab Syst 77: $115-121$

Stohs SJ, Bagchi D (1995) Oxidative mechanisms in the toxicity of metal ions. Free Radic Biol Med 18:321-336. doi:10.1016/08915849(94)00159-H

$\mathrm{Yu} \mathrm{X-Z,} \mathrm{Gu} \mathrm{J-D} \mathrm{(2007)} \mathrm{Accumulation} \mathrm{and} \mathrm{distribution} \mathrm{of} \mathrm{trivalent}$ chromium and effect on hybrid willow (Salix matsudana Koidz $\mathrm{X}$ alba L.) metabolism. Arch Environ Contam Toxicol 52:503511. doi:10.1007/s00244-006-0155-7

Yu X-Z, Gu J-D (2008) Effect of available nitrogen on phytoavailability and bioaccumulation of hexavalent and trivalent chromium in hankow willow (Salix matsudana Koidz). Ecotoxicol Environ Saf 70:216-222. doi:10.1016/j.ecoenv.2007.11.010

Yu X-Z, Gu J-D, Huang S-Z (2007) Hexavalent chromium induced stress and metabolic responses in hybrid willow. Ecotoxicol 16:299-309. doi:10.1007/s10646-006-0129-6 